\title{
Access to 2-Amino-3-arylthiophenes by Base-catalyzed Redox Condensation Reaction between Arylacetonitriles, Chalcones, and Elemental Sulfur
}

\author{
Thi Thu Tram Nguyen, ${ }^{\mathrm{b}}$ Van Anh Le, ${ }^{\mathrm{a}}$ Pascal Retailleau, ${ }^{\mathrm{a}}$ and Thanh Binh Nguyen ${ }^{\mathrm{a}, *}$ \\ a Institut de Chimie des Substances Naturelles, CNRS UPR 2301, Université Paris-Sud, Université Paris-Saclay, 1 \\ avenue de la Terrasse, 91198 Gif-sur-Yvette, France \\ Email: thanh-binh.nguyen@cnrs.fr \\ b Department of Chemistry, Faculty of Science, Can Tho University of Medicine and Pharmacy, Vietnam
}

Received: ((will be filled in by the editorial staff))

Supporting information for this article is available on the WWW under http://dx.doi.org/10.1002/adsc.201\#\#\#\#\#.((Please delete if not appropriate))

\begin{abstract}
A straightforward access to 2-amino-3arylthiophenes has been developed via one-pot two-step three-component reaction of arylacetonitriles, chalcones and elemental sulfur. The first step consists in a DBUcatalyzed formation of Michael adduct between arylacetonitriles and chalcones. The second step is a cascade of DABCO-catalyzed sulfuration of the Michael adduct with elemental sulfur followed by an oxidative cyclization to afford thiophenes. Compared to the Gewald reactions and related transformations which are limited in acetonitriles bearing a methylene group activated by an $\alpha$-substituted electron withdrawing group as substrates, our method can be applied to a wide range of arylacetonitriles and requires only catalytic amounts of DBU and DABCO. The developed reaction opens an access to 3-aryl-2-aminothiophenes complementary to classical Gewald reactions with high degree of structural diversity and atom efficiency.
\end{abstract}

Keywords: sulfur; 2-aminothiophene; chalcone, arylacetonitrile; oxidative sulfuration

Substituted 2-aminothiophenes occupy an important place in thiophene chemistry because of their fascinating biological activities ${ }^{[1]}$ such as antiviral ${ }^{[2]}$ anticancer, ${ }^{[3]}$ anti-tubercular, antimicrobial, ${ }^{[4,5]}$ antioxidants, ${ }^{[6]}$ kinase inhibitors, ${ }^{[7]}$ as well as various beneficial effects on neurological disorders. ${ }^{[8]}$ Olanzapine, sold under the trade name Zyprexa among others, is an atypical antipsychotic primarily used to treat schizophrenia and bipolar disorder. Bentazepam possesses anxiolytic, anticonvulsant, sedative and skeletal muscle relaxant properties.

A large number of 2-aminothiophene-containing molecules with promising pharmacological effects and have been approved by the FDA (Fig. 1). For example, T-62, which is fused 2-amino-3-benzoylthiophene analog, is a selective allosteric enhancer of the adenosine A receptor ${ }^{[9]}$ whereas Tinoridine is a nonsteroidal anti-inflammatory drug with antiperoxidative properties. Osseor or strontium ranelate is used to treat osteoporosis. Raltitrexed is used in cancer chemotherapy by inhibiting thymidylate synthase. Brotizolam used in the short-term treatment of insomnia.

Another attractive feature of 2-aminothiophenes is their ability to act as starting points for the synthesis of bioactive thiophene-containing heterocycles, conjugates and hybrids. ${ }^{[10]}$

In general, various synthetic pathways developed by Gewald in $1960 \mathrm{~s}^{[11]}$ have become key approach employed in the synthesis of Gewald 2aminothiophenes (Scheme 1). ${ }^{[12]}$

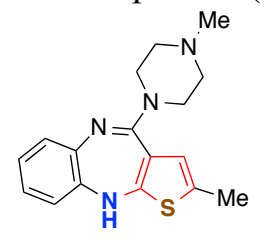

Zyprexa or Olanzapine $\mathrm{NC} 2 \mathrm{Sr}^{2+}$<smiles>N#Cc1c(N(CC(=O)[O-])CC(=O)[O-])sc(C(=O)[O-])c1CC(=O)[O-]</smiles>

Osseor<smiles>O=C1CN=C(c2ccccc2)c2c(sc3c2CCCC3)N1</smiles>

Bentazepam<smiles>CCOC(=O)c1c(N)sc2c1CCN(Cc1ccccc1)C2</smiles>

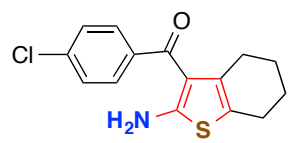

T-62<smiles></smiles><smiles>Cc1nnc2n1-c1sc(Br)cc1C(c1ccccc1Cl)=NC2</smiles>

Figure 1. Selected examples of 2-aminothiophene drugs

In this series of reactions, $\alpha$-sulfanyl carbonyl compounds $\mathbf{B}$, which can exist as dimeric forms $\mathbf{A}$ were allowed to react with acetonitriles $\mathbf{C} \alpha$ substituted by an electron withdrawing group in the presence of a basic catalyst (usually secondary or tertiary amine such as $\mathrm{Et}_{3} \mathrm{~N}$ or piperidine). 
Alternatively, $\alpha, \beta$-unsaturated nitrile $\alpha$-substituted by an electron withdrawing group $\mathbf{E}$ were treated sulfur and amine. In a one-pot three-component version, $\mathbf{E}$ was obtained in situ from the Knoevenagel-Cope condensation of carbonyl compounds $\mathbf{D}$ with nitriles $\mathbf{C}$.

Other methods were also developed based on reaction conditions optimization ${ }^{[13]}$ or extension of substrate scope ${ }^{[14]}$ of the Gewald reaction or as alternative approaches to 2-aminothiophene derivatives starting from organosulfur compounds. ${ }^{[15]}$

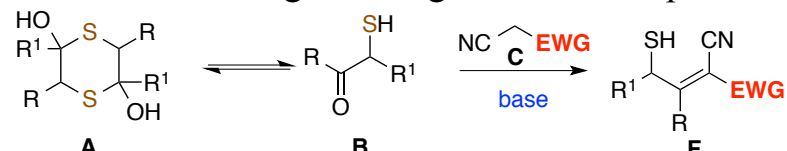

$$
\prod_{\text {base }}^{\text {P }}
$$

Scheme 1. 2-Aminothiophenes by Gewald reaction

However, it should be noted that the Gewald reaction as well as all of its variations and most of the alternative synthetic methods of 2-aminothiophenes have an intrinsic limitation: the obtained 2aminothiophene products should have an electron withdrawing group (EWG) in the position 3 of the thiophene ring such as ester, amide, thioamide, cyano, ketone etc.

Mechanistically, the first step is a Knoevenagel condensation between the carbonyl compounds B (or D) and the acetonitriles $\mathbf{C}$ to produce the substituted acrylonitriles $\mathbf{F}$ (or E, respectively). Such a condensation is feasible if the methylene group of the cyano compounds $\mathbf{B}$ ( or $\mathbf{D}$ ) is more acidic than that of the acetonitriles $\mathbf{C}$ to avoid the competing formation of carbanion during this step as well as the use of stronger bases for deprotonation. This explains why the presence of an EWG on the cyano compound $\mathbf{C}$ plays a central role to the success of the Gewald reaction. Consequently, the amount of structural diversity these methods can generate is inherently limited.

To avoid this limitation, we envisioned an alternative approach in which we could install a neutral functional group in the position 3 of the thiophene ring such as aryls. More importantly, the high degree of structural diversity should be supported by using starting materials that are readily available in a wide range of structures.

As part of our goal to discover new reactivities of elemental sulfur in organic synthesis, ${ }^{[16]}$ our attention was drawn to the development of strategy for direct incorporation of sulfur atom from elemental sulfur to organic scaffolds. ${ }^{[17]}$ We report here a versatile synthesis of 2-amino-3-arylbenzothiophenes via basecatalyzed three-component reaction of sulfur with readily available arylacetonitriles and chalcones. It is worth noting that chalcones are very readily available as commercialized chemicals or via synthesis from
Claisen-Schmidt condensation of acetophenones and benzaldehydes. To the best of our knowledge, this type of sulfur-involved multicomponent access to 2-amino3-arylthiophenes has never been explored.

At the outset of this study, we performed an exploratory reaction of chalcone 1a with phenylacetonitrile 2a and elemental sulfur. Given the fact that the preparation of Michael adducts from phenylacetonitrile and chalcone and the subsequent sulfuration require both a base catalyst, it was assumed that there is an opportunity for combining both the reactions in one-pot using only one basic catalyst. Based on our previous experience with elemental sulfur, we initially chose DABCO ${ }^{[18]}$ as a basic catalyst and DMSO as an oxidant additive. ${ }^{[19]}$ To our delight, heating a mixture of phenylacetonitrile 1a and chalcone 2a with elemental sulfur (2 equiv) and DABCO (20 mol \%) DMSO at $80{ }^{\circ} \mathrm{C}$ for $16 \mathrm{~h}$ led to the desired product 3aa in moderate yield. The low efficiency of this seminal trial was inarguably due to the competing formation of side products issued from direct attack of elemental sulfur on 1a and 2a (Scheme 2).

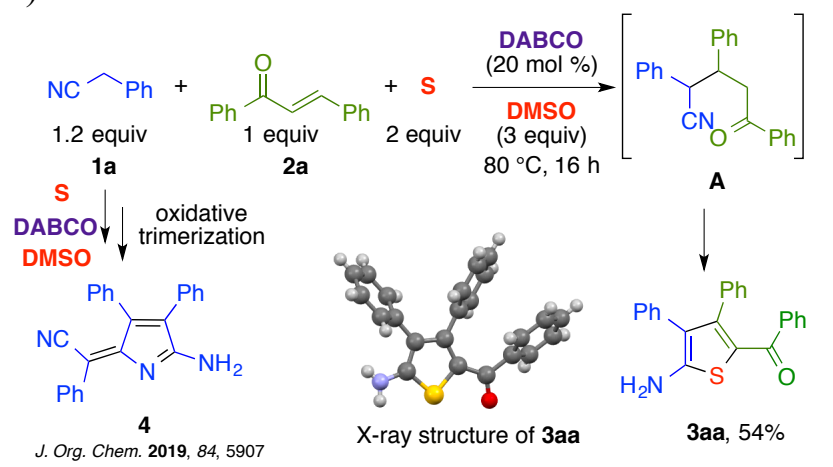

Scheme 2. Initial three-component synthesis of 3aa

Trimer 4 was isolated in 25\% yield (based on 1a) was identified as one of the side products. ${ }^{[18]} \mathrm{A}$ radical solution for this issue is to transform as completely as possible both organic substrates $\mathbf{1 a}$ and 2a into Michael adduct $\mathbf{A}$ prior to the addition of elemental sulfur. For this purpose, we optimized the reaction conditions for the C-C bond formation step with some selected results presented in Table 1.

Gratifyingly, this initial step proceeded at $80{ }^{\circ} \mathrm{C}$ with significant rate (entry 1 ) and accomplished after 4 $\mathrm{h}$ (entry 2) when DABCO was used as a base. However, $\mathrm{DABCO}$ was shown to be catalytically inactive at $\mathrm{rt}$. At this stage, we considered the possibility to replace DABCO by a more performant base catalyst. This catalyst should not only promote efficiently the C-C bond formation step but also not have any detrimental impact on the subsequent sulfurating cyclization.

Among the nitrogen bases ( $N$-methylpiperidine, $N$ methylmorpholine, pyridine, triethylamine, DIPEA, DBU) tested in catalytic amounts (20 mol \%), we quickly identified DBU as an excellent candidate since this catalyst could promote the expected reaction even at rt with a catalyst loading as low as $1 \mathrm{~mol} \%$ in only 30 min (entries 4-6). Other bases were shown to be 
either less efficient than DABCO ( $N$-methylpiperidine, $\mathrm{N}$-methylmorpholine, pyridine, triethylamine, DIPEA) or totally absent of catalytic activity (pyridine) but all of them were totally inactive at rt.

We noted also that replacing DMSO in this reaction by other additives (DMF, DMAc, $N$-methylpiperidone, THF, dioxane, $\mathrm{CH}_{2} \mathrm{Cl}_{2}$ ) or performing the reaction in the absence of DMSO led to significantly lower reactivity. For practical reasons, the set of conditions in entry 5 was applied for all subsequent reaction with chalcones. In most cases, Michael adduct $\mathbf{A}$ was formed as a mixture of two diastereomers in a 2:3 ratio. Since both newly for stereocenters will be destroyed after the formation of thiophene ring, this low diastereoselectivity had no impact on the next step although a slight difference in reactivity could occur.

Table 1. Optimization of the initial Michael addition ${ }^{\mathrm{a}}$

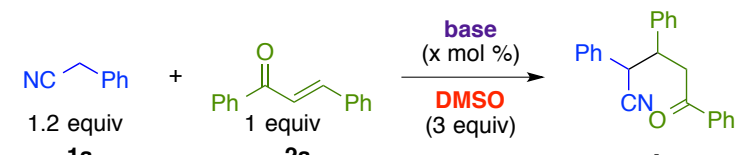

$1 \mathrm{a}$

$2 a$

A

$\begin{array}{lllll}\text { Entry } & \text { Base (x mol \%) } & \mathrm{T}\left({ }^{\circ} \mathrm{C}\right) & \mathrm{t} & \mathbf{A}(\%)^{\mathrm{b}} \\ 1 & \text { DABCO (20) } & 80 & 20 \mathrm{~min} & 50 \\ 2 & \text { DABCO (20) } & 80 & 4 \mathrm{~h} & 100 \\ 3 & \text { DABCO (20) } & 25 & 16 \mathrm{~h} & 0 \\ 4 & \text { DBU (20) } & 25 & 10 \mathrm{~min} & 100 \\ \mathbf{5} & \text { DBU (5) } & \mathbf{2 5} & \mathbf{3 0 ~ \mathbf { ~ m i n }} & \mathbf{1 0 0} \\ 6 & \text { DBU (1) } & 25 & 30 \mathrm{~min} & 100\end{array}$

a Reaction conditions: phenylacetonitrile 1a $(0.6 \mathrm{mmol})$, chalcone $2 \mathrm{a}(0.5 \mathrm{mmol})$, DMSO $(0.1 \mathrm{~mL}, 1.5 \mathrm{mmol})$ and base (x mol \%). ${ }^{b}$ Yield determined by ${ }^{1} \mathrm{H}$ NMR of the crude reaction mixture.

At this stage, we were ready to evaluate the subsequent sulfuration by adding powder sulfur to the reaction mixture and heating at $80^{\circ} \mathrm{C}$ for $16 \mathrm{~h}$ (Scheme 3 ). Contrary to our expectations, the mixture of Michael adducts remained unchanged, potentially due to strong interaction of elemental sulfur with DBU to such an extent that this base was not available to deprotonate cyanoketone A. At this point, we turned our attention to add DABCO (20 mol \%) as a basic catalyst for this second step. To our delight, 2aminothiophene 3aa was formed in good yield. Other bases ( $N$-methylpiperidine, $N$-methylmorpholine, pyridine, triethylamine, DIPEA, pyridine) were shown to be less efficient.

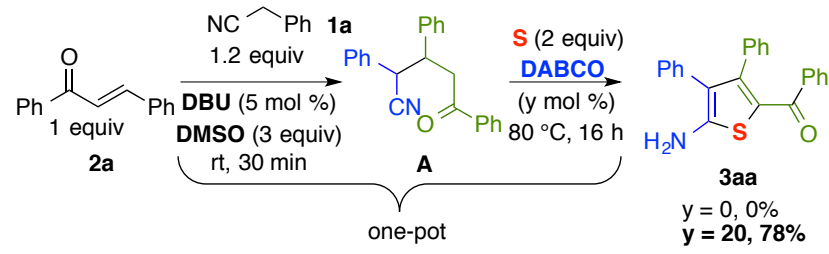

Scheme 3. Access to 3aa - optimization of the second step
With the optimized conditions (Table 1, entry 5) for two-step one-pot reaction, we set out to explore the scope of the arylacetonitriles 1 (Scheme 4). The reaction worked with arylacetonitriles bearing a wide range of substituents including methyl (3ab-3ad), methoxy (3ae-3ah), halogen (3ai-3an) in different position of the aromatic ring with moderate ${ }^{[20]}$ to good yields. Notably, the presence of an ortho-substituent was not problematic (3ad, 3ag, 3ak, 3an). Substrate bearing an electron withdrawing groups such as trifluoromethyl or nitro or 2-pyridyl ring reacted in the same manner and gave the expected products in reasonable yields.

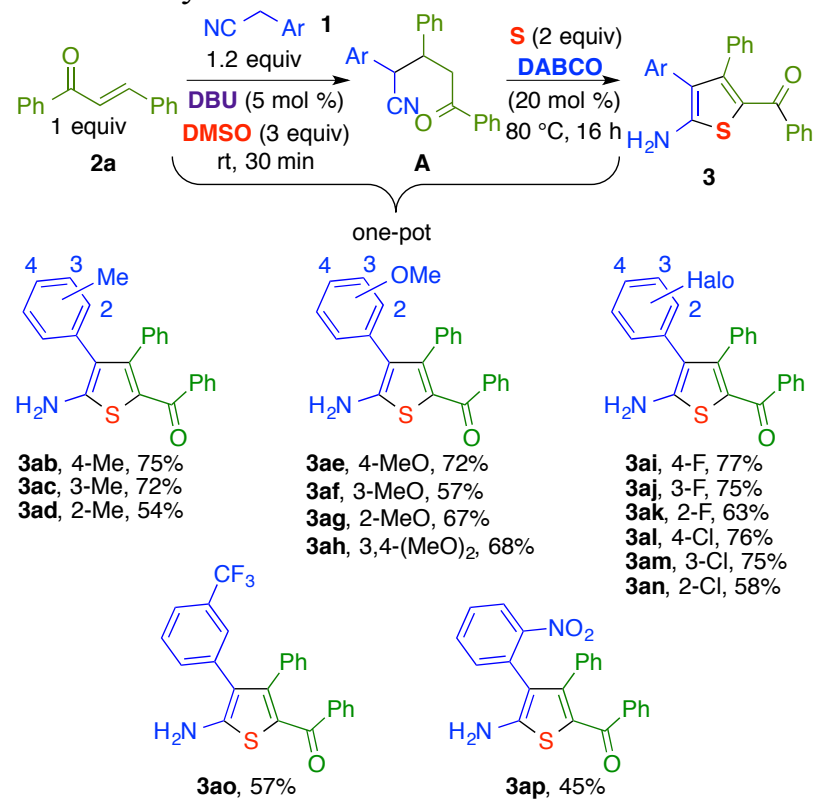

Scheme 4. Reaction of nitriles $\mathbf{1}$ with chalcone $\mathbf{2 a}$ and $\mathrm{S}_{8}$

Next, we further evaluated the scope of the chalcones 2 by varying both aryl groups of this component (Scheme 5). Functional groups such as methyl, methoxy or chloro did not influence significantly on the efficiency of the reaction, the expected products could be obtained in good yields in all these cases (3ba-3ha).

We witnessed the same outcome with chalcones bearing an electron with drawing group such as cyano (product 3ia) and nitro (products $\mathbf{3 j a}$ and $3 \mathbf{k a}$ ).

It should be noted that hydrogen sulfide, a possible by-product of the oxidative sulfuration step could attack these EWG including addition to the cyano group to provide thioamide and reduction of the nitro group to lower oxidation state nitrogen derivatives. However, such undesirable reactions were avoided in all these cases, unarguably due to the presence of DMSO which could act as a hydrogen sulfide scavenger by oxidizing $\mathrm{H}_{2} \mathrm{~S}$ into starting elemental sulfur. ${ }^{[19]}$

Similarly, thienyl derivatives 3la-3na could be obtained in the same manner as for phenyl analogs.

Finally, reaction with alkylated conjugated enones such as cyclohexanone or benzylideneacetone followed the same pathway and led to the expected 
thiophenes 3oa-3pa, despites in lower yields, potentially due to side reactions relating to enolization of the alkyl moieties.

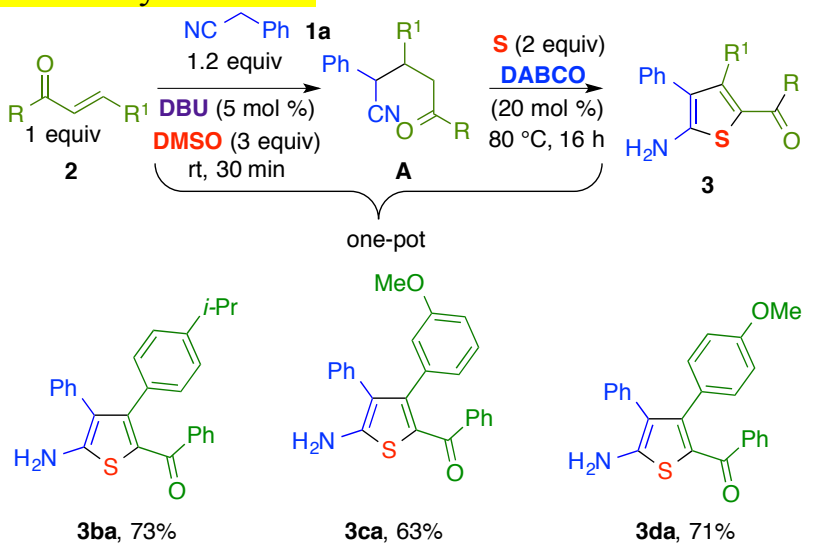

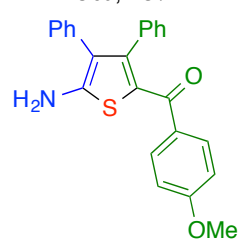

3ea, $68 \%$

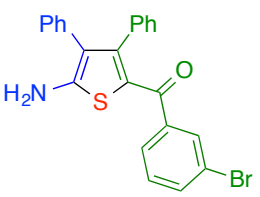

3ha, $58 \%$<smiles>Nc1sc(C(=O)c2ccc([N+](=O)[O-])cc2)c(-c2ccccc2)c1-c1ccccc1</smiles>

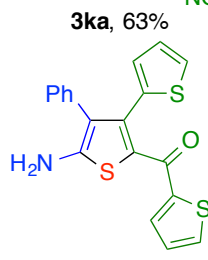

3na, $63 \%$

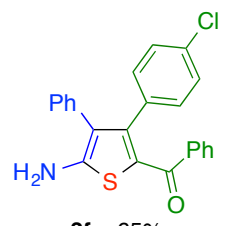

3fa, $65 \%$

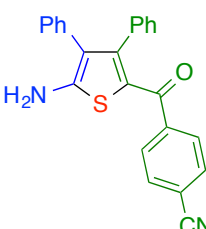

3ia, $53 \%$<smiles>Nc1sc(C(=O)c2ccccc2)c(-c2ccsc2)c1-c1ccccc1</smiles>

3la, $67 \%$<smiles>Nc1sc2c(c1-c1ccccc1)CCCC2=O</smiles>

3oa, $52 \%$

from 1a $(0.5 \mathrm{mmol})$ an cyclohex-2-en-1-one $(0.75 \mathrm{mmol})$

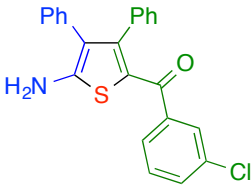

3ga, $65 \%$

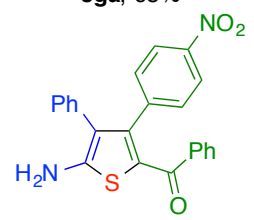

3ja, $73 \%$<smiles>Nc1sc(C(=O)c2ccccc2)c(-c2ccccc2)c1-c1ccccc1</smiles>

3ma, $71 \%$<smiles>CC(=O)c1sc(N)c(-c2ccccc2)c1-c1ccccc1</smiles>

3pa, $43 \%$
Scheme 5. Reaction of nitrile $\mathbf{1 a}$ with enones $\mathbf{2}$ and $\mathrm{S}_{8}$

We were curious to see whether this process would extend to a classical cyanoacetate derivative 5 (Scheme 6). To our surprise, while the first steps of Michael addition and sulfurative cyclization proceeded without any difficulty, the aromatization could not be achieved despite more drastic conditions (heating at $100{ }^{\circ} \mathrm{C}$, prolonging the reaction time up to $72 \mathrm{~h}$ ). The structure of the obtained product 7 was determined as a transdihydrothiophene by X-ray crystallography. This may be explainable based on a less favorable conformation of the 4-phenyl and 5-benzoyl group. Indeed, due to a stronger conjugation between the 2 -amino and 3 -ester groups in 7 compared to 2-amino and 3-phenyl groups in 3aa, dehydrogenation step would be more difficult for $3 a a$.

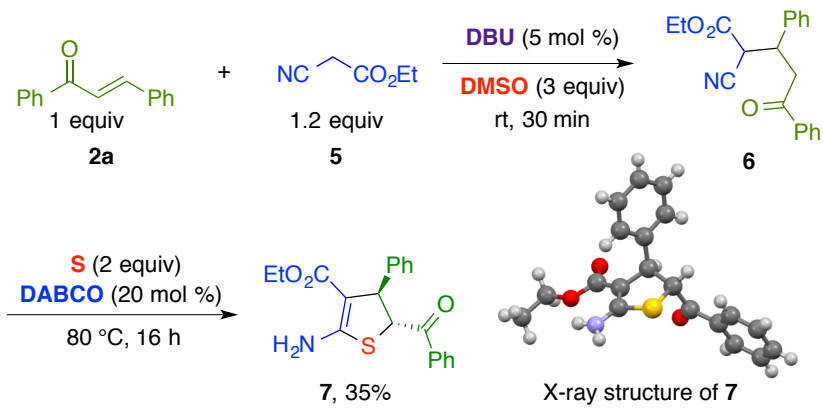

Scheme 6. Reaction of nitrile $\mathbf{5}$ with chalcone $\mathbf{2 a}$ and $\mathrm{S}_{8}$

While details of the oxidative sulfuration and cyclization steps were not fully understood, we proposed a plausible mechanism (Scheme 7). Sulfuration of Michael adduct A occurred via its carbanion $\mathbf{B}$ and complex $\mathbf{C}$ between DABCO and sulfur to provide cyanopolysulfide D. Desulfurative cyclization of cyano $\mathbf{D}$ would lead to thioimine $\mathbf{E}$, which could undergo a tautomerization into thioenamine F. Dehydrogenation of $\mathbf{F}$ could be achieved via DABCO-catalyzed-formation of carbanion $\mathbf{G}$ stabilized by the benzoyl group and could involve activated sulfur species $\mathbf{C}$ via a sequence of sulfuration of carbanion $\mathbf{G}$ to $\mathbf{H}$ and elimination of hydrogen (poly)sulfide from $\mathbf{H}$.

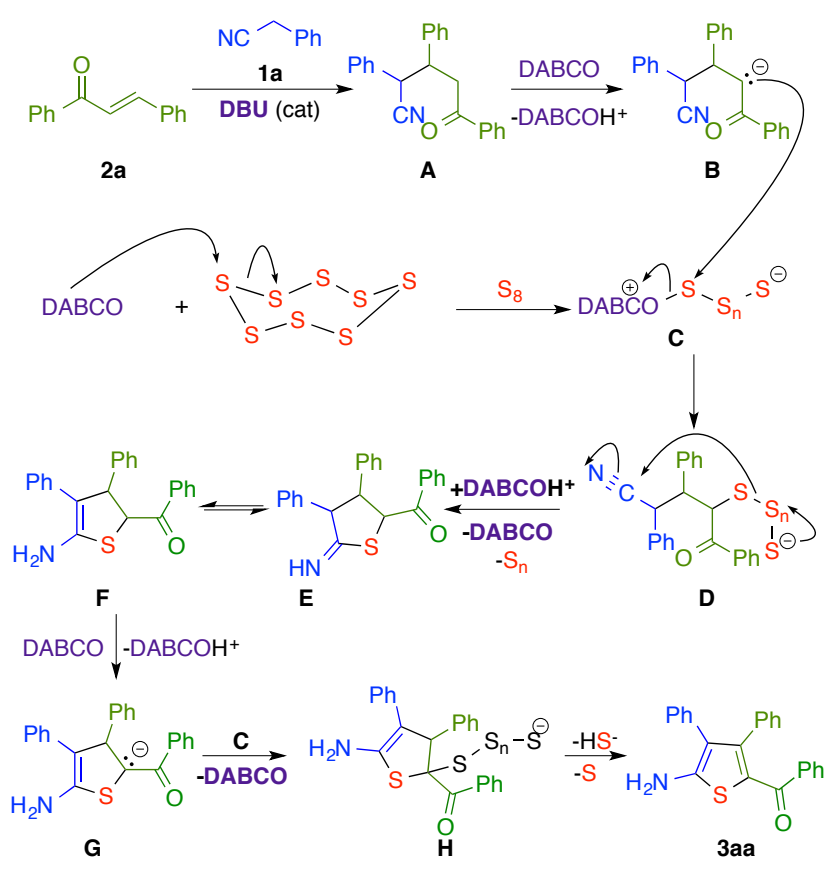

Scheme 7. Proposed mechanism

In conclusion, we have developed a threecomponent synthesis of 2-aminothiophenes involving arylacetonitriles $\mathbf{1}$, chalcones $\mathbf{2}$ and elemental sulfur. This one-pot transformation consists in two steps: (i) initial formation of Michael adduct A catalyzed by $\mathrm{DBU}$; and (ii) oxidative sulfuration and cyclization of adduct $\mathbf{A}$ with elemental sulfur catalyzed by DABCO. 
Compared to the previous approaches based on Gewald reactions which required acetonitrile substrates bearing an $\alpha$-substituted EWG, our method could be applied successfully to arylacetonitriles, opening a convenient and complementary access to 3aryl-2-aminothiophenes. Moreover, unlike most of the previous syntheses based on Gewald reactions using stoichiometric amount or in excess base additive, only catalytic amounts of DBU and DABCO were needed in our reaction. In term of atom efficiency, the global transformation of our method consists in a removal of only two hydrogen atom.

Once again, this reaction showcased elemental sulfur as a versatile tool for organic synthesis of organosulfur compounds in an inexpensive and straightforward manner. We hope that this method will attract the attention of both medicinal and material chemists.

\section{Experimental Section}

General procedure for the synthesis of 2aminothiophenes 3 and dihydrothiophene 7

A mixture of acetonitrile 1 ( 0.6 mmol, 1.2 equiv $)_{2}$ chalcone $2(0.5 \mathrm{mmol}, 1$ equiv) and DBU' $4 \mathrm{mg}, 0.025$ mmol, $5 \mathrm{~mol} \%$ ), and DMSO (0.1 mL, $1.5 \mathrm{mmol}, 3$ equiv) was stirred at $\mathrm{rt}$ for $30 \mathrm{~min}$ in a $7-\mathrm{mL}$ tube. Sulfur (32 mg, $1 \mathrm{mmol})$ and DABCO $(0.1 \mathrm{mmol})$ was next added to the tube and the resulting mixture was stirred and heated at $80^{\circ} \mathrm{C}$ for $16 \mathrm{~h}$. The reaction mixture was purified by column chromatography on silica gel $\left(\mathrm{CH}_{2} \mathrm{Cl}_{2}\right.$ to $\left.\mathrm{CH}_{2} \mathrm{Cl}_{2}: \mathrm{EtOAc}\right)$ to afford the product as a yellow solid.

CCDC-1951373 and CCDC-1951374 (compounds 7 and 3aa respectively) contain the supplementary crystallographic data for this paper. These data can be obtained free of charge from The Cambridge Crystallographic Data Centre via www.ccdc.cam.ac.uk/data_request/cif.

\section{Acknowledgements}

We thank ICSN-CNRS and Dr. A. Marinetti (ICSN-CNRS) for helpful support.

\section{References}

[1] For an excellent review on biological activities of 2aminothiophene derivatives, see: K. Bozorov, F. Nie, J. Zhao, H. A. Aisa, Eur. J. Med. Chem. 2017, 140, 465.

[2] J. Desantis, G. Nannetti, S. Massari, M. L. Barreca, G. Manfroni, V. Cecchetti, G. Palù, L. Goracci, A. Loregian, O. Tabarrini, Eur. J. Med. Chem. 2017, 138, 128.

[3] a) A. S. S. H. Elgazwy, M. M. Edrees, N. S. M. Ismail, J. Enzyme Inhib. Med. Chem. 2013, 28, 1171; b) K. Bozorov, H. R. Ma, J. Y. Zhao, H. Q. Zhao, H. Chen, K. Bobakulov, X. L. Xin, B. Elmuradov, K. Shakhidoyatov, H. A. Aisa, Eur. J. Med. Chem. 2014, 84, 739; c) K. Bozorov, J. Y. Zhao, L. F. Nie, H. R. Ma, K. Bobakulov, R. Hu, N. Rustamova, G. Huang, T. Efferth, H. A. Aisa, RSC Adv. 2017, 7, 31417.
[4] a) S. Al-Mousawi, M. El-Apasery, H. Mahmoud, Molecules 2013, 18, 7081; b) P. S. Fogue, P. K. Lunga, E. S. Fondjo, J. De Dieu Tamokou, B. Thaddée, J. Tsemeugne, A. T. Tchapi, J. R. Kuiate, Mycoses 2012, 55, 310; c) L. Scotti, M. T. Scotti, E. D. O. Lima, M. S. D. Silva, M. D. C. A. D. Lima, I. D. R. Pitta, R. O. D. Moura, J. G. B. D. Oliveira, R. M. D. D. Cruz, F. J. B. Mendonça-Junior, Molecules 2012, 17, 2298.

[5]a) S. Thanna, S. E. Knudson, A. Grzegorzewicz, S. Kapil, C. M. Goins, D. R. Ronning, M. Jackson, R. A. Slayden, S. J. Sucheck, Org. Biomol. Chem. 2016, 14, 6119; b) C. Scheich, V. Puetter, M. Schade, J. Med. Chem. 2010, 53, 8362.

[6] a) L. Tavadyan, Z. Manukyan, L. Harutyunyan, M. Musayelyan, A. Sahakyan, H. Tonikyan, Antioxidants 2017, 6, 22; b) K. Madhavi, G. Sree Ramya, Asian J. Pharm. Clin. Res. 2017, 10, 95.

[7] V. Oza, S. Ashwell, L. Almeida, P. Brassil, J. Breed, C. Deng, T. Gero, M. Grondine, C. Horn, S. Ioannidis, D. Liu, P. Lyne, N. Newcombe, M. Pass, J. Read, S. Ready, S. Rowsell, M. Su, D. Toader, M. Vasbinder, D. Yu, Y. Yu, Y. Xue, S. Zabludoff, J. Janetka, J. Med. Chem. 2012, $55,5130$.

[8] C. Ballatore, A. B. Smith, V. M. Y. Lee, J. Q. Trojanowski, K. R. Brunden, Expert Opin. Ther. Pat. 2014, 24, 355.

[9] G. Kazuhiro, H. Masao, I. Hiroshi, Biochem. Pharmacol. 1977, 26, 11.

[10] a) T. Nasr, S. Bondock, S. Eid, Eur. J. Med. Chem. 2014, 84, 491; b) E. F. Silva-Júnior, E. P. S. Silva, P. H. B. França, J. P. N. Silva, E. O. Barreto, E. B. Silva, R. S. Ferreira, C. C. Gatto, D. R. M. Moreira, J. L. SiqueiraNeto, F. J. B. Mendonça-Júnior, M. C. A. Lima, J. H. Bortoluzzi, M. T. Scotti, L. Scotti, M. R. Meneghetti, T. M. Aquino, J. X. Araújo-Júnior, Bioorg. Med. Chem. 2016, 24, 4228.

[11] a) K. Gewald, Chem. Ber. 1965, 98, 3571; b) K. Gewald, E. Schinke, Chem. Ber. 1966, 99, 2712; c) K. Gewald, E. Schinke, H. Böttcher, Chem. Ber. 1966, 99, 94; d) V. K. Gewald, M. Kleinert, B. Thiele, M. Hentschel, J. Prak. Chem. 1972, 314, 303.

[12] For reviews on Gewald reaction, see: a) K. Gewald, Chem. Heterocycl. Compd. 1976, 12, 1077; b) Z. Puterova, A. Krutosikova, D. Veghc, Arkivoc 2010, 1, 209; c) Y. Huang, A. Domling, Molec. Divers. 2011, 15, 3; d) A. El-Mekabaty, Synth. Commun. 2014, 44, 1; e) R. W. Sabnis, Color. Technol. 2016, 132, 49; f) R. Shah, P. K. Verma, Chem. Central J. 2018, 12, 137.

[13] For selected examples, see: a) L. Ma, L. Yuan, C. Xu, G. Li, M. Tao, W. Zhang, Synthesis 2013, 45, 45; b) G. Revelant, S. Dunand, S. Hesse, G. Kirsch, Synthesis 2011, 2935; c) B. P. McKibben, C. H. Cartwright, A. L. Castelhano, Tetrahedron Lett. 1999, 40, 5471; d) T. Wang, X. G. Huang, J. Liu, B. Li, J. J. Wu, K. X. Chen, W. L. Zhu, X. Y. Xu, B. B. Zeng, Synlett. 2010, 1351; e) H. Zhang, G. Yang, J. Chen, Z. Chen, Synlett. 2004, 3055. 
[14] a) W. Shao, S. J. Kaldas, A. K. Yudin, Chem. Sci. 2017, 8, 4431; b) J. Thomas, S. Jana, M. Sonawane, B. Fiey, J. Balzarini, S. Liekens, W. Dehaen, Org. Biomol. Chem. 2017, 15, 3892.

[15] a) L. Ge, Z. Wang, X. An, X. Luo, W. Deng, Org. Biomol. Chem. 2014, 12, 8473; b) H. Zali-Boeini, F. Pourjafarian, J. Sulfur Chem. 2012, 33, 639; c) X. Luo, L. Ge, X. An, J. Jin, Y. Wang, P. Sun, W. Deng, J. Org. Chem. 2015, 80, 4611; d) I. Talbi, C. Alayrac, J. Lohier, S. Touil, B. Witulski, Org. Lett. 2016, 18, 2656; e) L. K. Ransborg, L. Albrecht, C. F. Weise, J. R. Bak, K. A. Jørgensen, Org. Lett. 2012, 14, 724.

[16] For reviews on the use of elemental sulfur in organic synthesis, see: a) T. B. Nguyen, Adv. Synth. Catal. 2017, 359, 1106; b) T. B. Nguyen, Asian J. Org. Chem. 2017, $6,477$.

[17] For selected recent works on the synthesis of thiophenes from elemental sulfur, see: a) G. Zhang, H. Yi, H. Chen, C. Bian, C. Liu, A. Lei, Org. Lett. 2014, 16, 6156; b) L. Meng, T. Fujikawa, M. Kuwayama, Y. Segawa, K. Itami, J. Am. Chem Soc. 2016, 138, 10351; c) B. Li, P. Ni, H. Huang, F. Xiao, G.-J. Deng, Adv. Synth. Catal. 2017, 359, 4300; d) Z. Wang, Z. Qu, F. Xiao, H. Huang, G.-J. Deng, Adv. Synth. Catal. 2018, 360, 796; e) H. Huang, Q. Wang, Z. Xu, G.-J. Deng, Adv. Synth. Catal. 2019, 361, 591; f) H. Huang, Z. Xu, X. Ji, B. Li, G.-J. Deng, Org. Lett. 2018, 20, 4917; g) J. Liu, Y. Zhang, Y. Yue, Z. Wang, H. Shao, K. Zhuo, Q. Lv, Z. Zhang, J. Org. Chem. 2019, DOI: 10.1021/acs.joc.9b01586. For our recent work on the use of elemental sulfur as building block for the synthesis of thiophene compounds, see: (h) T. B. Nguyen, P. Retailleau, Green Chem. 2018, 20, 387; i) T. B. Nguyen, P. Retailleau, Org. Lett. 2018, 20, 186; j) T. B. Nguyen, P. Retailleau, Org. Lett. 2017, 19, 4858.

[18] T. B. Nguyen, P. Retailleau, J. Org. Chem. 2019, 84, 5907.

[19] a) T. B. Nguyen, L. A. Nguyen, P. Retailleau Org. Lett. 2019, 21, 6570; b) T. B. Nguyen, J. Y. Hou, P. Retailleau, Adv. Synth. Catal. 2019, 361, 3337; c) T. B. Nguyen, P. Retailleau Adv. Synth. Catal. 2019, 361, 3588; d) L. A. Nguyen, P. Retailleau, T. B. Nguyen, Adv. Synth. Catal. 2019, 361, 2864; e) T. B. Nguyen, L. P. A. Nguyen, T. T. T. Nguyen, Adv. Synth. Catal. 2019, 361, 1787; f) T. B. Nguyen, P. Retailleau, Org. Lett. 2019, 21, 279; g) T. B. Nguyen, P. Retailleau, Adv. Synth. Catal. 2018, 360, 2389.

[20] The yields described here were the results of a two-step sequence and obviously depended on the first step. If the conversion of the first step was not complete, i.e. arylacetonitriles and chalcones were not consumed totally, these two compounds could react with sulfur to give many products. One of which issued from an oxidative trimerization of arylacetonitriles were previously described (reference 18) by our group. The separation of all these side products from the principal products was shown to be not easily and this could lower the global yield. 


\section{COMMUNICATION}

Access to 2-Amino-3-arylthiophenes by Basecatalyzed Redox Condensation Reaction between Arylacetonitriles, Chalcones, and Elemental Sulfur

Adv. Synth. Catal. Year, Volume, Page - Page
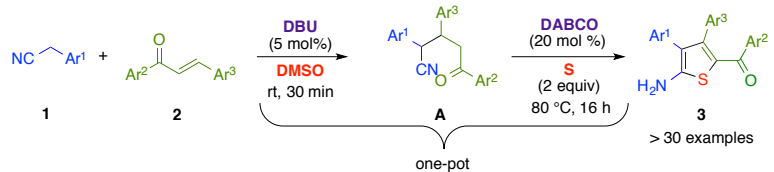

Thi Thu Tram Nguyen, ${ }^{\mathrm{b}}$ Van Anh Le, ${ }^{\mathrm{a}}$ Pascal

Retailleau, and Thanh Binh Nguyen ${ }^{a}$, 